\title{
Conflicts Induced by Different Responses to Land Expropriation Among the Farmers Involved During Urbanization in China
}

\author{
Haijun Bao ${ }^{1}$, Xiaohe $W^{1}$, Haowen Wang ${ }^{2}$, Qiuxiang $\mathbf{L i}^{1}$, Yi Peng ${ }^{1}$, \\ Shibao Lu' \\ ${ }^{1}$ School of Public Administration, Zhejiang University of Finance \& Economics, 18 Xueyuan Street, Xiasha \\ Higher Education Park, Hangzhou, Zhejiang Province, China \\ ${ }^{2}$ School of Business Administration, Zhejiang University of Finance \& Economics, 18 Xueyuan Street, Xiasha \\ Higher Education Park, Hangzhou, Zhejiang Province, China \\ Correspondence should be addressed toliqx@zufe.edu.cn
}

Journal of Artificial Societies and Social Simulation 22(1) 7, 2019

Doi: 10.18564/jasss.3931 Url: http://jasss.soc.surrey.ac.uk/22/1/7.html

Received: 06-04-2018 Accepted: 07-12-2018 Published: 31-01-2019

\begin{abstract}
Expropriation of collectively-owned land has become an important realistic path for achieving urban development and new urbanization in China considering the shortage of state-owned land. During this process, farmers involved in land expropriation are often in conflict with one another because of the asymmetry of their interests. Such conflicts have a considerable effect on social harmony and stability. However, few studies have investigated such conflict of interests between farmers. Therefore, this research analyzed game behavior for the conflict of interests among farmers. A two-dimensional symmetric evolutionary game model and a multiagent simulation experiment were used to explore the conflicts induced by the farmers' different responses to land expropriation. This research finds that the changing strategy choices of farmers in the evolutionary game on collectively owned land expropriation are the main reasons for the occurrence of villager' confrontations and "nail households". Results provide targeted policy recommendations for local governments to promote cooperation among farmers, thereby enhancing social harmony. The findings also serve as references for other countries and regions in dealing with intra-conflict of interests in land expropriation.
\end{abstract}

Keywords: Conflict of Interests, Land Expropriation, Evolutionary Game, Multi-Agent Simulation, Farmers

\section{Introduction}

1.1 Land expropriation occurs frequently throughout China's rapid urbanization. Along with the gradual saturation of state-owned land supply, the nonagricultural use of collectively owned land provides large-scale nonagricultural construction land for China's fast economic development and promotion of new urbanization (Ye et al. 2011: Wu et al. 2017, Peng et al. 2018b). Expropriation of collectively owned land for expansion of cities and towns serves as an important realistic path for encouraging new urbanization. According to the national statistical yearbook, areas of land requisition increased from 301937.28 hectares in 2007 to 373202.76 hectares in 2015. However, various actual contradictions and "nail households" (residents who refuse to relocate during land expropriation) can occur easily during land expropriation along with the excessive pursuit of urbanization (Jin \& Chen 2017). Farmers involved in land expropriation attempt to maximize their own economic interests, otherwise their psychological and emotional needs are neglected. These irrational responses from farmers have a serious effect on social harmony and hinder sustainable urbanization.

1.2 Various conflicts that emerge during land expropriation present barriers for achieving sustainable urbanization. Land acquisition and demolition between urban and rural areas are conducted separately and independently, indicating that clear "dual-track" characteristics currently exist between the collectively owned land expropriation system and the corresponding land market selling system (Ding \& Lichtenberg 2011): Wu et al. 2018). Whether for farmland or urban land, nationalization by the government and entrance into the land primary market in a unified way are necessary to transfer land use rights by various forms, such as transfer, lease, or authorized 
operation. The dual-track system generates the difference between the compensation price of the land acquisition and the sale price in the market (Tan \& Tu|2009). In addition, land acquisition conflict in the rural-urban fringe zone is frequent because the needed collectively owned land is usually located at the edge of the urban area (Bao et al. 2014: Bao \& Peng 2016 Peng 2015). Land expropriation conflict is not only a serious social problem but also an important political issue related to the vital interests of farmers and the harmony and stability of social development. Numerous agricultural lands are levied, causing the widening economic gap between urban and rural areas, the increased number of land-expropriated farmers, and political mass disturbance of farmers. In recent years, many vicious conflict events have occurred because of land expropriation, most of which transpired between farmers and local governments. Moreover, numerous conflict events on collectively owned land expropriation have occurred among farmers because of their unequal interests or dissatisfaction with interest requirements, causing villagers' confrontations and "nail households". Land expropriation conflicts cause negative social effects, that have a direct effect on the stability and development of Chinese society, especially its rural society, and influence the implementation of new urbanization strategy.

1.3 However, few studies have investigated the conflict of interest among farmers. Existing research on land expropriation conflicts in China focused mainly on the reasons and compensation standards involved. Perry \& Wong (1985) examined rural land expropriation conflicts in China since the reform and opening-up and believed that the conflicts manifest mainly in the competition between villages and villagers for public resources, such as land. Zou \& Oskam (2007) explored the standard compensation for market value during land expropriation in China. Wehrmann (2008) argued psychological factors constitute the underlying cause of land conflicts. Land expropriation conflicts have also been investigated from the perspective of relevant stakeholders' behavior. Zhu 2013) affirmed that frequent land expropriation conflicts are caused by the transformation between the state and social relations and the resulting tension. In addition, several scholars conducted qualitative studies on the influencing factors of the game strategy between the central government, local governments, rural collective organization, land-expropriated farmers, and land developers (Ke \& He 2006; Wang 2007, Tan \& Tu 2009). Zhong (2013) claimed that the advantages of local governments as decision makers render them prone to illegal behavior in relation to land expropriation. In addition, several researchers have advocated land expropriation humanization and attention toward the psychological demands on farmers to reduce their worries about life [Zhang et al. 2005; Bao et al. 2017, 2018).

1.4 This study aims to explore the conflicts induced by the different responses of farmers to land expropriation. Game theory and simulation approach are employed to assist the analysis. Section 2 offers relevant literature review on land expropriation conflicts. Section 3 introduces the evolutionary game model and the simulation experiment used to verify the propositions. Section 4 provides a sensitivity analysis of all parameters of the evolutionary game model to check the influence of the parameters on farmers. Section 5 presents an in-depth discussion based on the findings of the simulation experiment and proposes ways to promote the cooperation of farmers involved in land expropriation. Section 6 concludes the study and specifies future research directions.

\section{Literature Review}

\section{Land expropriation conflict in China}

2.1 Land expropriation conflicts are the most important type of land conflicts. Most studies focused on the concept of land conflicts, and only few have investigated land expropriation conflicts. The concept of land expropriation conflicts appears to be missing in the academe. Meng (2010) defined land expropriation conflicts as an interactive channel in the confrontational psychological or behavioral process caused by intensified contradictions in which beneficiaries acquire interests during land expropriation. Yuan (2015) asserted that land expropriation conflicts refer mainly to a confrontational interaction process on benefits, in which stakeholders obtain land resources and unequal interest distribution during land expropriation. Land conflicts are caused by different incentives specified in various definitions. Current studies on the incentives of the objective environment of land conflicts have been conducted mainly from two perspectives: (1) land compensation and (2) the legal system. From a land compensation perspective, land expropriation conflicts are generated by the vagueness and unfairness of property rights and the insufficiency of compensation and protection. This perspective usually involves three theoretical explanations: the definitions of property right theory (Fischel \& Shapiro 1988), market mechanism theory (Zhou 2004), and public interest theory (Huang \& Wang 2002). From a legal system perspective, rights contradictions exist because expropriation rights and land planning belong to public power, 
whereas real estate property and land development rights are private in the constitution of rights for collectively owned land expropriation (Shen 2006). The procedural anomie of the legal system triggers primarily the abuse of land expropriation rights, and the defects in the procedures and rules of land expropriation manifest in the vagueness of standards and the lack of a guarantee of procedural rights in land expropriation Cheng 2006. Land expropriation conflicts during urbanization can be considered a mutually contradictory interactive process, in which villagers, the government, developers, and other participants fight over land benefits, power, and rights (Bao et al.2017). Therefore, several scholars have explored land expropriation conflict from an incentive perspective. Li (2007) and Meng (2010) argued that the impetus based on the effectiveness unconformity of the conflict subject further stimulates land expropriation conflicts. Tang 2009) found that the main reason for land expropriation conflict is the complex relationship in the interest game of relevant stakeholders.

2.2 Various major stakeholders are involved in land expropriation conflicts. Zhang 2009 asserted that the main stakeholders involved in land expropriation conflicts include farmers, central and local governments, enterprises, and village committees. Luo 2009) corroborated that five stakeholders are included in land expropriation conflicts: (1) developers, (2) farmers, (3) village committees or village representatives, (4) superior governments, and (5) local governments (which have a dominant position). Tan \& Tu (2009) argued that the types of land expropriation conflicts involve chiefly conflicts between farmers and enterprises, farmers and local governments, farmers and rural collective economic organizations, enterprises and local governments, and rural collective economic organizations and local governments.

2.3 A game model can simulate the behaviors of stakeholders whose interests depend on one another (Peng et al. 2014; Bao et al.2015; Liang et al. 2016). Consequently, many scholars have adopted the game model to analyze the interaction among stakeholders of land conflicts (Yang|2013). Alston et al. (2000) developed a game model to simulate the antagonistic behavior between a land seizer and a landlord. Hotte (2001) established a conflict game model based on best land use for investment decision making. Li (2007) used the expanded threat game model to simulate game bargaining of government officials and farmers. On the basis of equilibrium probability, Zou et al. (2012) proposed that the behaviors of the central and local governments and farmers entail a dynamic game process in land expropriation conflicts, and established a game model to assess the reasons for the conflicts. Measures have been proposed to address land expropriation conflicts. Several researchers have discussed solutions from different perspectives. Fang \& Chen (2007) proposed that opening up various economic and institutional channels are keys to addressing land expropriation conflicts. Ding (2007) argued that the governing conflicts should be conducted by perfecting legislation, constantly changing governmental functions, and improving legislation and justice support. Tang (2009) claimed that establishing an interactive system for the benefit of the political network can address current contradictions in the land expropriation for China's urbanization. Liu \& Chen (2012) suggested the research paradigm of "land risk" based on risk society theory to govern conflicts. From the perspective of farmers' satisfaction, Liu et al. (2012a) proposed that such scenario not only achieves procedural justice prior to monetary compensation but also ends the embezzling and withholding of land compensatory funds among village collectives in land expropriation. He 2013) argued that the combination of social and land security can alleviate land conflicts. The transformation of land conflicts also solves the problem. Baranyi \& Weitzner 2006) stated that the approach of transformation has a significant advantage over the management, prevention, and resolution of conflict. According to a conflict assessment perspective, several researchers established early warning management mechanisms based on the conflict evaluation system of land expropriation conflicts in China (Chen et al. 2009, Tan \& Qi 2010). From a public system construction perspective, Zhong (2009) pointed out that the governance of land expropriation conflicts should emphasize governmental responsibility and gradually establish the consciousness of multiple principal responsibilities to construct a governing network for land expropriation conflicts with diversified stakeholders.

2.4 However, few studies have investigated the conflict of interests among farmers involved in land expropriation. The effect of land expropriation on farmers is twofold: adverse and beneficial. To a certain extent, farmers are rational people who consider the costs and benefits of land expropriation ( $\mathrm{Li}$ 2007). After land expropriation, farmers lose their land and their land-related rights and interests, such as land income and disposal rights (Tan 2006. Their dependence on a familiar environment and their social relations are also affected or broken, which increases their survival costs. Generally, farmers do not observe or consider the benefits of land expropriation but instead concern themselves fully with the cost of land loss from their own perspectives. Therefore, to reduce profit loss from land expropriation, farmers find means to compete with village organizations and local governments when they are dissatisfied with the standards of land compensation. In addition, farmers involved in land expropriation often unconsciously produce an inimical emotion during this process, which breeds conflicts. Land expropriation conflicts, including "nail households" and villager' confrontations, seriously affect village harmony, cause real challenges, and long-term hidden danger to rural stability, and increase rural governance difficulty. 


\section{Methods in land expropriation conflict research}

2.5 Various qualitative methods, including case studies and normative research, have been used to investigate land expropriation conflicts worldwide. Amman \& Duraiappah (2004) conducted field studies in the Narok region of Kenya and ascertained that different perceptions of national and regional leaders of land system exacerbate conflicts that usually evolve into violence. Boydell (2003) selected Palestine, Cambodia, Sri Lanka, Colombia, Guatemala, Burundi, and Mozambique as case study areas and used the theory and method of conflict dynamics to determine if land policy is a key factor in land expropriation conflicts. Ramirez 2002) proposed a conceptual framework of land conflict management based on soft system methodology and created a conceptual map of this management. Liu et al. (2012b) carried out an empirical research on the monetary compensation and influencing factors of land expropriation and found that institutional adjustment and farmer participation are necessary in governing land expropriation conflicts. Li et al. (2006) divided the root causes of land conflicts in rural areas into three aspects based on theories of philosophy and political economy: (1) land conflict stakeholder, (2) land conflict ontology, and (3) institutional arrangement deficit.

2.6 Several quantitative methods have also been used to examine land expropriation conflicts. To analyze the transformation between avoidance, competition, cooperation, and reconciliation of land conflicts, Boydell (2001) employed the image method and analytic hierarchy process to establish models of double correlation and benefit power and relationship. De Wit (2002) investigated measures of reducing land conflicts by utilizing an optimized model in land use planning. Yang et al. (2008) studied the compensation standards for land expropriation from the perspectives of the Gini coefficient and Lorenz curve. Using a regression model,Tu (2009) analyzed the induced factors of conflicts quantitatively and concluded that the most influential factor is the sense of fairness in land expropriation compensation. Numerous scholars utilized conflict analysis to add a sense of conceptual risk to the player of conflicts and propose an improved solution (Zhang 1990). However, the conflict analysis method in China, whether as theoretical or empirical research, remains immature. In summary, the most obvious drawback of the quantitative approach is the difficulty in addressing unquantifiable factors.

2.7 Multi-agent simulation is an alternative method used to investigate land expropriation conflicts. In general, game theoretical models can describe the hypothetical relations among agents, which are valuable tools for illustrating multi-agent systems (Le Bars \& Le Grusse 2008). In other words, game modeling is an appropriate method to understand the function of multi-agent systems (Barreteau et al. 2001). Therefore, many scholars combine game theory with multi-agent simulation in their research. Douma et al. (2012) applied the simulation game to a multi-agent system for barge handling in a seaport. Nishino et al. (2017) utilized multi-agent simulation methodology and game modeling to analyze the effects of strategy imitation on cooperation network formation and the differences in the game players' abilities. In the domain of land expropriation conflicts, however, most current studies focused on the application of the game model to evaluate the game among stakeholders. By contrast, research on behavioral simulation in collectively owned land expropriation remains deficient. The behavior of stakeholders and the interaction between stakeholders and the environment in collectively owned land expropriation conflicts is complex. Moreover, the agent modeling method can combine the micro-behavior and emerging macroscopic phenomena of complex systems by modeling and simulating basic elements and their interactions in the systems (Filatova et al.2009, Schwarz et al.|2012, Polhill et al. 2010). Applying the agent-based modeling method to land expropriation conflicts among farmers not only analyzes the evolutionary gambling behavior of farmers, but also enriches the application direction of the method and achieves a breakthrough in current research techniques and existing theory of land expropriation conflicts.

\section{Research Method}

3.1 This section discusses the logic of the farmers' behavior from the evolutionary game theoretical perspective. The simulation platform is then used to simulate the game model for the visualization of its evolution laws. Figure 1 summarizes these relationships. The model code is available here: https://www.comses.net/codebaserelease/c65119e8-5c36-4334-a8e9-31dce39921dd/

3.2 According to evolutionary game theory, the interactive effects among individual agents with differing decision processes and capabilities can be investigated using the evolutionary game model (Windrum et al.2007). Therefore, we construct a model on the conflict of interests among farmers involved in land expropriation and analyze its evolutionary stable strategies and payoff functions. A corresponding simulation experiment was conducted for different farmer responses to land expropriation by using the Netlogo simulation platform. The consistency between simulation results and the evolutionary game stable strategies (evolutionary game results) were verified. A sensitivity analysis for all parameters of the evolutionary game model was also provided to further check the influence of parameters on farmers involved in land expropriation. 


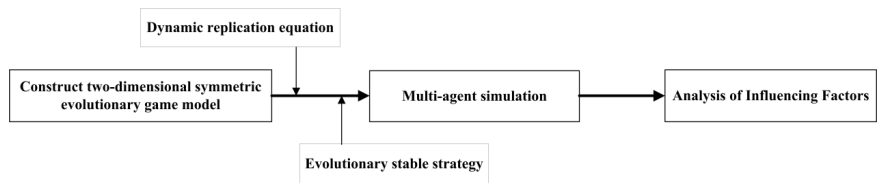

Figure 1: The theoretical model of the research.

\section{Model specification}

3.3 The basic hypothesis of evolutionary game theory is the bounded rationality hypothesis. This theory assumes that individual behavior is not optimized in reality and that individual decision making is achieved by various dynamic processes, such as imitation, learning, and mutation (Friedman 1998, Bao et al. 2015). This theory includes two aspects: (1) dynamic replication and (2) evolutionary stability strategy (ESS). Dynamic replication is the principal mechanism of agent imitation and strategy adjustment in the evolutionary game. An ESS is a strategic manifestation of population stability and an evolution trend of evolutionary game agents $\mid \mathrm{Xie}$ 2010: $\mathrm{Li}$ et al. 2017).

3.4 Farmers involved in land expropriation are bounded rationality actors influenced by the objective environment and other game players. Strategy selection is an evolutionary process wherein efforts and imitation are based continuously on bounded rationality and uncertainty. Such selection is also a time-varying dynamic game process. When farmers differ in terms of capacity for information acquisition and handling, their level of knowledge, unfair benefit distribution, and game process become uncertain. This uncertainty may lead to multiple states, such as the villagers' confrontation and "nail households" in land acquisition and demolition processes.

\section{Assumptions of the model}

3.5 To simplify the analysis, three basic assumptions are made:

1. Random pairing of two pairs of games;

2. Bounded rationality economic man;

3. Symmetrical evolutionary game.

3.6 Assumption 1 indicates that although the decision makers in the two groups constituted by farmers face all individuals in the opposing group, the model assumes that the game is repeated between the individuals of the two groups in random pairing. Individuals may change strategies by mean of repeated games to obtain optimal benefits; hence, this game is regarded as a mixed-strategy Nash equilibrium (Lee 2018. This study selects individuals randomly from a large group and conducts a symmetrical two-player game where all of them are born to "be specified" to implement a mixed strategy at the beginning of the game. If the optimal equilibrium strategy can withstand errors and the deviation of the interference caused by bounded rationality can still be restored with minimal interference, then the strategy is identified as a stable evolution and the equilibrium is known as ESS (Weibull 1996; Phillips-Alonge 2018).

3.7 Assumption 2 indicates that farmers involved in land expropriation are bounded rationality economic people, which mean that farmers cannot select the best strategy at the onset, but they do so after continuous trial and imitation to find the optimal strategy. The two sides take the principle of optimal strategy from their demands and the actual situation to pursue their own benefit maximization. The players cannot identify and select such strategy at the beginning of the game because the bounded rationality hypothesis is the basic hypothesis of evolutionary game theory, and they find or choose the ESS through continuous comparison, learning, and imitation.

3.8 Assumption 3 indicates that the two game players are similar and that the different gains obtained from the two sides are caused by their dissimilar actions. The game strategies of all farmers are cooperative and noncooperative. Cooperation means that farmers agree with land expropriation, whereas noncooperation implies that farmers will hinder land expropriation. In this case, the conflict of interests will occur easily. Under the model, the game is a two-dimensional symmetric one dependent on the attributes of the players. 


\section{Model analysis of payoff function}

3.9 To simulate the behavior of farmers involved in land expropriation conflicts, the payoff functions of the two players are analyzed initially. This research assumes that the total amount of income obtained by farmers from land expropriation is $R_{0}$. When both sides adopt a cooperative strategy, their earnings are $\frac{R_{0}}{2}$. Conversely, when they adopt a non-cooperative strategy, the cost of farmers in response to other farmers who adopt cooperative strategies is $C_{f}$, and the cooperative cost of land expropriation is $C_{0}$.

3.10 The model results are as follows and are summarized in Table1,

1. The harmony of villagers (cooperation, cooperation) and payment functions of both game agents are $\frac{R_{0}}{2}-C_{0}$. All landless farmers form a unified cooperation resolution to match the works of land acquisition and demolition.

2. The resistance of villagers (noncooperation, noncooperation) and the payment function of both game agents are $-C_{f}$. The two game players select the noncooperation strategy at this point. Such choice may be attributed to the dissatisfaction of farmers with acquisition compensation or the division of opinion among farmers (Peng et al.|2018a). Thus, both sides resist land acquisition and demolition.

3. The conflict of villagers (cooperation, noncooperation) and payment functions are $R_{0}-C_{0}$ and $-C_{f}$, respectively. Several farmers involved in land expropriation choose a cooperative strategy, whereas the rest of the villagers resist land acquisition and demolition because of unfair treatment or clique confliction among them or for other reasons. Both sides expect the other party to change the current strategy to limit the corresponding executor costs of the conflict that has emerged.

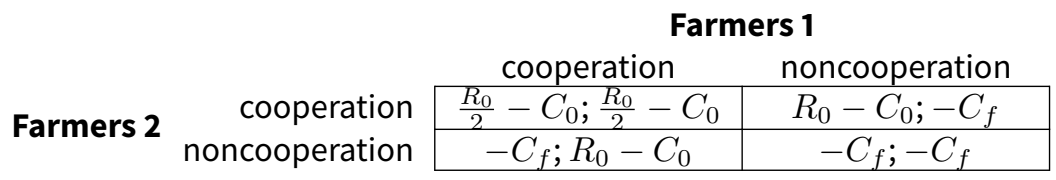

Table 1: The payment matrix of farmers involved in collectively owned land expropriation.

$$
\begin{aligned}
& R_{0} \text { : Total amount of income obtained from land expropriation } \\
& C_{0} \text { : Cooperative costs of farmers involved in land expropriation } \\
& C_{f} \text { : Coping costs of farmers involved in land expropriation }
\end{aligned}
$$

\section{Analysis of dynamic replication equation and evolutionary stable strategies}

3.11 Assume that the proportion of farmers who adopt the cooperative strategy is $x$ and the proportion of those who take non-cooperative strategies is $1-x$, where $x$ is the function of time $t$.

3.12 The average profit, which refers to the cooperative strategy adopted by farmers, is $U_{1}$.

$$
U_{1}=x\left(\frac{R_{0}}{2}-C_{0}\right)+(1-x)\left(R_{0}-C_{0}\right)
$$

3.13 The average profit, which indicates the non-cooperative strategies adopted by farmers, is $U_{2}$.

$$
U_{2}=x\left(-C_{f}\right)+(1-x)\left(-C_{f}\right)
$$

3.14 The average benefit of farmers is $\bar{U}$.

$$
\bar{U}=x U_{1}+(1-x) U_{2}
$$

3.15 Subsequently, the dynamic changing rate of ratio $x$ (which denotes farmers who choose the cooperative strategy) can be expressed as follows:

$$
F(x)=\frac{d x}{d t}=x\left(U_{1}-\bar{U}\right)=x(1-x)\left(U_{1}-U_{2}\right)=x(1-x)\left[R_{0}-C_{0}+C_{f}-x \frac{R_{0}}{2}\right]
$$


3.16 To solve the differential equations presented above, the three following stable solutions can be obtained:

$$
x_{1}^{*}=0 ; \quad x_{2}^{*}=1 ; \quad x_{3}^{*}=\frac{2\left(R_{0}-C_{0}+C_{f}\right)}{R_{0}}
$$

3.17 According to the nature of the ESS, a steady state must have good stability for small perturbations. According to the stability theorem of differential equations, when the interference causes $x$ to be below $x^{*}$, when the interference causes $x$ to be higher than $x^{*}, F(x)=\frac{d x}{d t}<0$, which means that the derivative $F^{\prime}(x)$ of $F(x)$ at the steady states (tangent slope) $F^{\prime}(x)$ is less than zero. Therefore,

$$
F^{\prime}(x)=R_{0}-C_{0}+C_{f}+2 x\left(C_{0}-\frac{3 R_{0}}{2}-C_{f}\right)+\frac{3 R_{0}}{2} x^{2}
$$

3.18 Based on the above equations, the following propositions can be made:

3.19 Proposition 1: When $R_{0}<C_{0}-C_{f}, x_{1}^{*}=0$ is the evolution strategy of the game.

Proof: When $R_{0}<C_{0}-C_{f}$, that is, $R_{0}-C_{0}+C_{f}<0$. In this situation, $x_{3}^{*}<0$, which is improper. Therefore, the dynamic replication equation has two equilibrium points: $x_{1}^{*}=0$ and $x_{2}^{*}=1$. Given that $F^{\prime}(1)>0$, $F^{\prime}(0)<0, x_{1}^{*}=0$ is the ESS of the evolutionary game, which has good stability for small perturbations.

Proposition 1 shows that when the total amount of income obtained from land expropriation by farmers $\left(R_{0}\right)$ is less than the differences between the costs of different strategies $C_{0}-C_{f}$ they adopted, numerous rational farmers will choose non-cooperative strategies. Simultaneously, villagers will resist collectively owned land expropriation.

3.20 Proposition 2: When $R_{0}>2\left(C_{0}-C_{f}\right), x_{2}^{*}$ is the evolution strategy of the game.

Proof: When $R_{0}>2\left(C_{0}-C_{f}\right)$, that is, $2\left(R_{0}-C_{0}+C_{f}\right)>R_{0}$. Simultaneously, $x_{3}^{*}>1$, which is improper. Therefore, the dynamic replication equation has two equilibrium points: $x_{1}^{*}=0$ and $x_{2}^{*}=1$. Given that $F^{\prime}(1)<0, F^{\prime}(0)>0, x_{2}^{*}=1$ is the ESS of the evolutionary game, which has good stability for small perturbations.

Proposition 2 indicates that when land acquisition compensation obtained by farmers and given by local government is more than twice the difference between the costs of different strategies $2\left(C_{0}-C_{f}\right)$ they adopted, numerous rational farmers will choose the cooperative strategy. Simultaneously, villagers will be harmonious during collectively owned land expropriation.

3.21 Proposition 3: When $C_{0}-C_{f}<R_{0}<2\left(C_{0}-C_{f}\right), x_{3}^{*}=\frac{2\left(R_{0}-C_{0}+C_{f}\right)}{R_{0}}$ is the evolution strategy of the game. Proof: When $C_{0}-C_{f}<R_{0}<2\left(C_{0}-C_{f}\right)$, that is, $0<x_{3}^{*}<1$, which can be selected. Therefore, the dynamic replication equation has three equilibrium points: $x_{1}^{*}=0, x_{2}^{*}=1$, and $x_{3}^{*}=\frac{2\left(R_{0}-C_{0}+C_{f}\right)}{R_{0}}$. Given that $F(1)>0,(0)>0, F^{\prime}\left(x_{3}^{*}\right)<0, x_{3}^{*}=\frac{2\left(R_{0}-C_{0}+C_{f}\right)}{R_{0}}$ is the ESS of the evolutionary game, which has good stability for small perturbations.

Proposition 3 shows that when the land acquisition compensation obtained by farmers and given by the local governments is more than the difference between costs of different strategies $C_{0}-C_{f}$ and is less than twice the difference among costs of different strategies $2\left(C_{0}-C_{f}\right)$ they adopted, the proportion of $\frac{2\left(R_{0}-C_{0}-C_{f}\right)}{R_{0}}$ farmers involved in land expropriation adopts the cooperative strategy, whereas the proportion of $\frac{C_{0}-R_{0}-2 C_{f}}{R_{0}}$ farmers adopts non-cooperative strategies. Simultaneously, the conflict of interests among villagers will occur during collectively owned land expropriation.

\section{Multi-agent simulation}

3.22 This research focuses on the symmetric evolution among farmers involved in land expropriation conflicts. Therefore, the existence of two types of agents in the model, farmers and real environment, is assumed. The real environment is a virtual subject that does not participate in creating the simulation model; instead, it aims mainly to generate the space of the agent and records the changes and numbers of other subjective attributes.

\section{Simulation process}

3.23 The simulation experiment of the conflict of interests among farmers involved in land expropriation is divided into four stages: 
3.24 First, a simulation model was set up based on the constructed evolutionary game model. Subsequently, the samples of agents (farmers) for the model were selected. Second, the rule set of behavioral strategy is constructed based on the established evolution model. The parameters were simultaneously chosen assuming relative value in accordance with the actual situation and enter them in the simulation platform for experimentation. Third, the design and revision of processes are carried out in the simulation implementation phase, and the simulation experiment is run on the existing simulation platform. Lastly, the simulation results of the experiment are observed and analyzed to determine whether the results are consistent with the evolution of stable equilibrium. The experiment is completed if the conditions are matched; otherwise, the parameters of simulation are set or the rule set of the behavioral strategy of the agent is re-entered along with the parameters in the simulation to run the experiment.

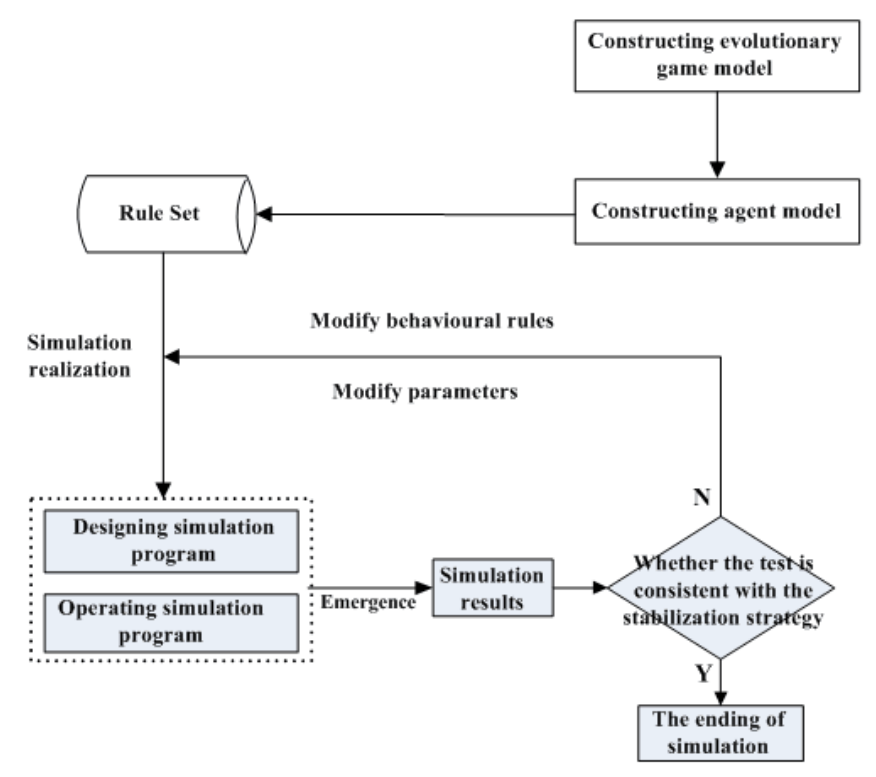

Figure 2: The flow chart of simulation experiment .

\section{Simulation requirements}

3.25 Assume that the system environment is a square area and the surrounding environment is initially distributed randomly by the agent of farmers involved in land expropriation, who move randomly in each model cycle. Therefore, the simulation parameters are set as follows:

1. Initial conditions: the total number of farmers involved in land expropriation is 200, and the number of cooperative and non-cooperative strategies is initially 1:1.

2. Simulation cycle: each simulation cycle corresponds to a month in the actual environment in a round of game time of farmers. The total duration of each test is $T$ cycle $(T \leq 80)$, and the entire test is equivalent to the simulation, which is less than seven years.

3. Behavioral rules: individual strategies can imitate other individual behaviors in the evolutionary process to maximize individual benefits. In the simulation experiment, individual behavioral rules follow the changes of the dynamic replication equation.

4. Termination condition: when the strategic proportion of the group in the system no longer changes with time, the game reaches a stable equilibrium solution, that is, no further variation occurs.

\section{Parameter setting}

3.26 According to the conditions of different propositions, three parameters affect the conflict of interests in land expropriation among farmers, namely, the total amount of income obtained by farmers from land expropriation $\left(R_{0}\right)$, the cooperative costs of farmers involved in land expropriation $\left(C_{0}\right)$, and the coping costs of farmers in response to other farmers who adopt cooperative strategies $\left(C_{f}\right)$. These parameters can be set in the following: 
1. According to the conditions of Proposition $1,\left(R_{0}-C_{0}+C_{f}<0\right)$, simulation parameters $\left(R_{0}=2, C_{0}=5\right.$, $C_{f}=2$ ) are selected. These parameters are entered into the initialized Netlogo platform to facilitate the simulation experiment.

2. According to the conditions of Proposition 2, $\left(R_{0}>2\left(C_{0}-C_{f}\right)\right)$, simulation parameters $\left(R_{0}=6, C_{0}=4\right.$, $\left.C_{f}=2\right)$ are selected These parameters are entered into the initialized Netlogo platform to conduct the simulation experiment.

3. According to the conditions of Proposition 3, $\left(C_{0}-C_{f}<R_{0}<2\left(C_{0}-C_{f}\right)\right)$, simulation parameters $\left(R_{0}=5, C_{0}=4, C_{f}=1\right)$ are selected. These parameters are entered into the initialized Netlogo platform to carry out the simulation experiment.

\section{Simulation}

3.27 (1) Figure 3 depicts the system results after multiple simulation cycles. Farmers involved in land expropriation select the non-cooperative stable strategy in this situation. The scenario presented above means that the stable solution of the system is $x_{1}^{*}=0$, and the result is consistent with the condition and conclusion of Proposition 1 .

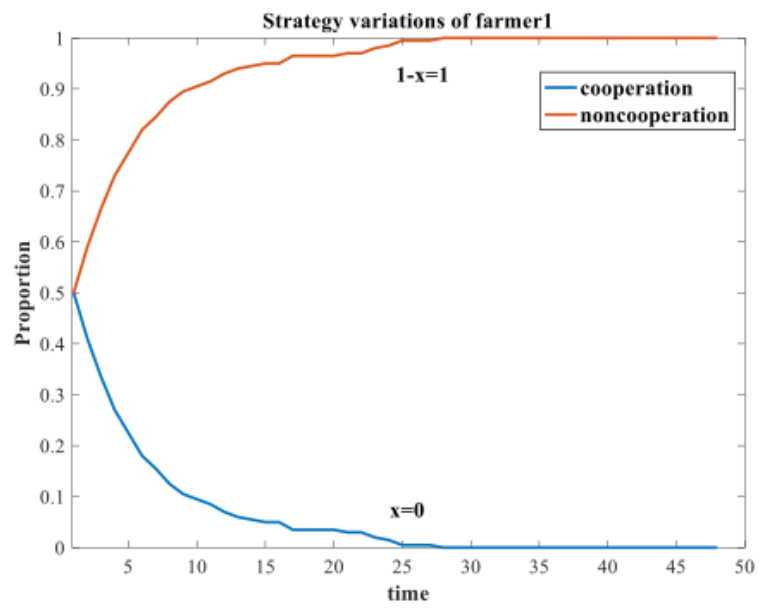

Figure 3: Simulation of the results under the condition of Proposition 1.

3.28 The simulation result in Figure 3 shows the case in which the initial ratio of cooperation and noncooperation among farmers is 0.5 . When the land acquisition compensation $R_{0}$ obtained by the farmers from the local governments is less than the difference between the costs of different strategies $C_{0}-C_{f}$ they adopted, agents with different strategies in the mutual gamble, who adopted the initial cooperative strategy based on the principle of maximizing revenue, gradually shift their strategy to the non-cooperative one by imitation. The stable results of the system involve non-cooperative strategies adopted by all agents. Mapping the simulation result to the real situation shows that, under these conditions, numerous rational farmers will choose non-cooperative strategies and resist collectively owned land expropriation.

3.29 (2) Figure 4 shows the system results after multiple simulation cycles. Farmers involved in land expropriation select the cooperative stable strategy in this situation. The scenario presented above means that the stable solution of the system is $x_{2}^{*}=1$ and that the outcome is consistent with the condition and conclusion of Proposition 2. 


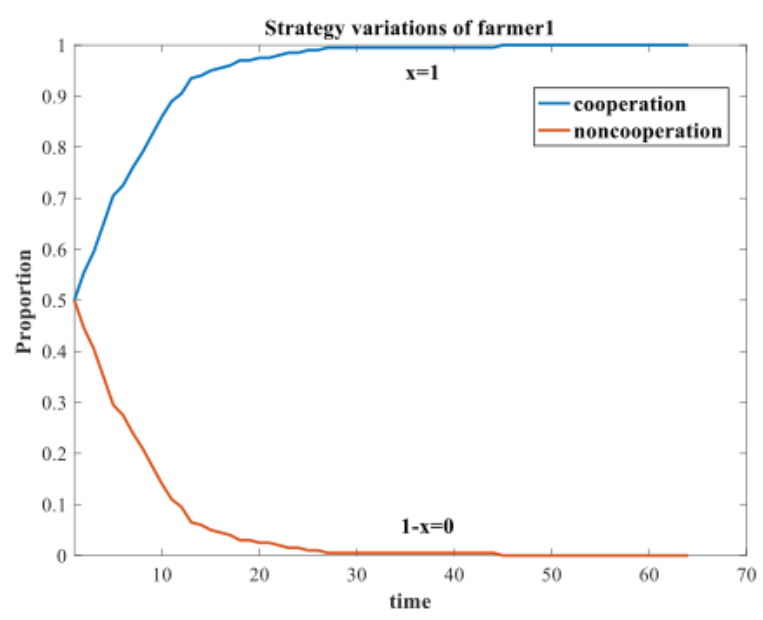

Figure 4: Simulation of the results under the condition of Proposition 2.

3.30 The simulation result in Figure 4 shows that for the case where the initial ratio of cooperation and noncooperation among farmers is 0.5 and the land acquisition compensation $R_{0}$ obtained by farmers from local governments is more than twice the difference between the costs of the different strategies $2\left(C_{0}-C_{f}\right)$ they adopted, agents with different strategies in the mutual gamble, who adopted the initial non-cooperative strategy based on the principle of maximizing revenue, gradually shift their strategy to the cooperative one by imitation. Moreover, the stable result of the system is obtained through the cooperative strategy adopted by all agents. Mapping the simulation results to the real situation shows that, under these conditions, numerous rational farmers will choose the cooperative strategy and be harmonious toward collectively owned land expropriation.

3.31 (3) Figure 5 shows the system results after multiple simulation cycles. The proportion of farmers who select the cooperative strategy is 0.8 . Subsequently, we take parameters $\left(R_{0}=5, C_{0}=4, C_{f}=1\right)$ into the equation $\left(x_{3}^{*}=\frac{2\left(R_{0}-C_{0}+C_{f}\right)}{R_{0}}\right)$ to obtain a stable system solution, which is $x_{3}^{*}=0.8$. The outcome is consistent with the condition and conclusion of Proposition 3.

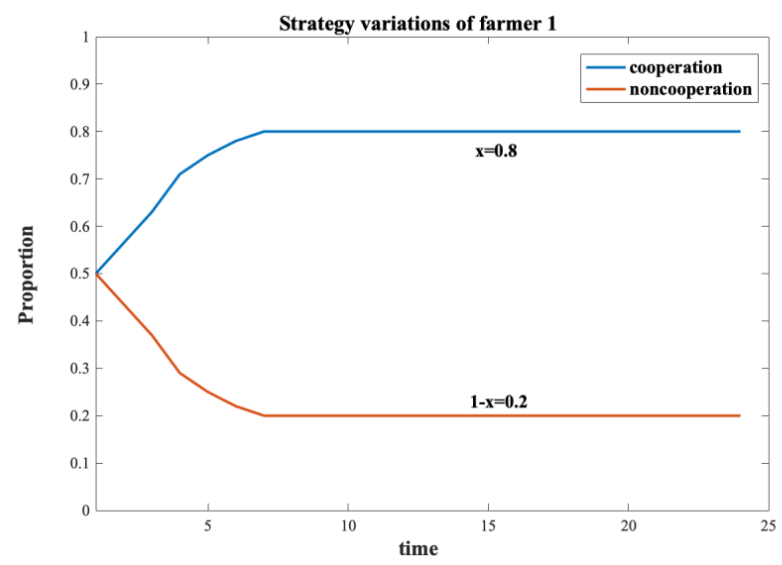

Figure 5: Simulation of the results under the condition of Proposition 3.

3.32 The simulation result in Figure 5 shows that in a case where the number of cooperative and non-cooperative strategies was initially 1:1 and the land acquisition compensation $R_{0}$ obtained by the farmers from the local governments is more than the difference between the costs of different strategies $C_{0}-C_{f}$ and is less than twice the difference among costs of different strategies $2\left(C_{0}-C_{f}\right)$ they adopted, the system reveals a stable result where $80 \%$ and $20 \%$ of the agents select cooperative and non-cooperative strategies, respectively, by imitating based on the principle of maximizing revenue after a long simulation period. Mapping the simulation results to the real situation indicates that the entire proportion of $\frac{2\left(R_{0}-C_{0}+C_{f}\right)}{R_{0}}$ farmers will adopt the cooperative strategy, but the proportion of $\frac{C_{0}-R_{0}-2 C_{f}}{R_{0}}$ farmers will adopt non-cooperative strategies under these conditions. Conflicts will appear on collectively owned land expropriation. 


\section{Analysis of Simulation Parameters}

4.1 The model assumes that farmers involved in land expropriation are bounded rational stakeholders. As mentioned, three parameters affect the conflict of interests in land expropriation among farmers: (1) the total amount of income obtained from land expropriation of farmers $\left(R_{0}\right),(2)$ the cooperative costs of farmers involved in land expropriation $\left(C_{0}\right)$, and (3) coping costs of farmers in response to other farmers who adopt cooperative strategies $\left(C_{f}\right)$. The influence of these parameters on the choice of responses by famers will be analyzed in this section. Based on the practical significance of dimensionless parameters, without loss of generality, we considered the relative size of these parameters and select them for analysis in several scenarios.

\section{Total amount of income obtained from land expropriation $\left(\mathrm{R}_{0}\right)$}

4.2 The effect of changes in the total amount of income by farmers' strategies is investigated by setting the parameter $R_{0}$ from 4 to 16 while fixing others. Figure 6 reveals that the time for farmers to choose cooperative strategies is shortened when the total amount of income increases from 4 to 16 . In other words, in the same time, farmers are more likely to choose cooperative strategy when the total amount of income is greater. A high income gained by farmers means that their rights and interests are guaranteed, which will increase the number of farmers who adopt cooperative strategies. This change is observed in real practice as farmers increasingly participate in such strategies when the income from land expropriation increases, especially because the reason for their resistance is the pursuit of greater benefits.

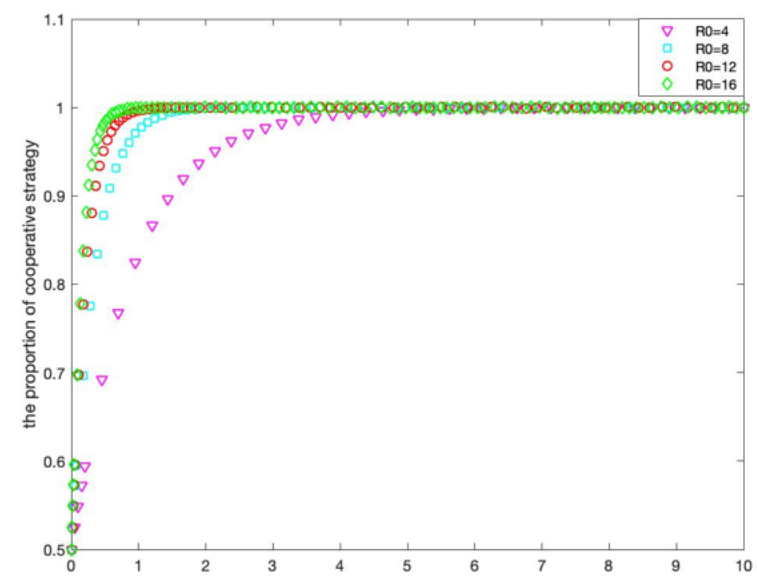

Figure 6: The effects of total amount of income on the evolutionary strategy of farmers.

\section{Cooperative costs of farmers involved in land expropriation $\left(\mathrm{C}_{0}\right)$}

4.3 Similarly, the cooperative costs of farmers involved in land expropriation $\left(C_{0}\right)$ are changed between 2 and 8 while fixing other parameters to investigate the effects of cooperative costs of land expropriation. Figure 7 shows that the time for farmers to choose cooperative strategies is extended when cooperative costs increase from 2 to 8 . In this process, farmers may be unwilling to adopt cooperative strategies as cooperative costs increase. When cooperative costs are high and stakeholder interests are not guaranteed, farmers would usually take various measures to protect their rights, which will result in conflicts. High cooperative cost usually results from information asymmetry, diversification of interest demands, and decentralization of decision-making in practice. This phenomenon is also observed in practice wherein the progress of land expropriation is usually slower with increasing cooperative cost. 


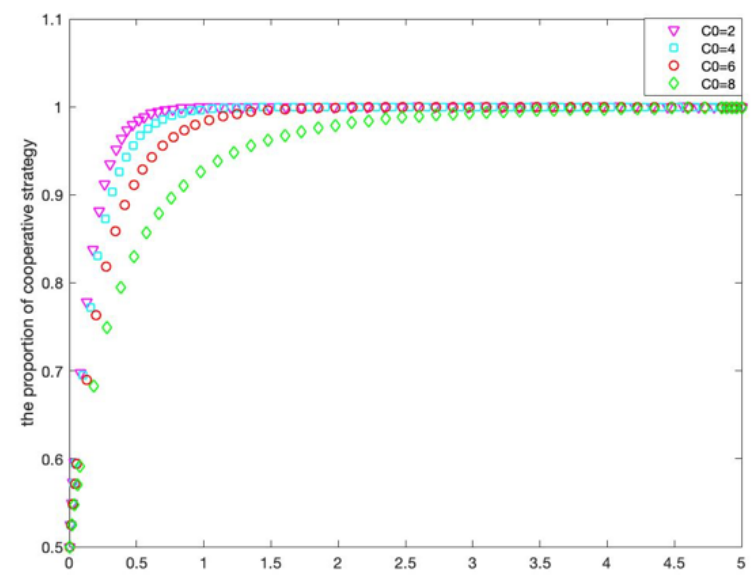

Figure 7: The effects of the cost of land expropriation on the evolutionary strategy of farmers.

\section{Coping costs of farmers involved in land expropriation $\left(\mathrm{C}_{\mathrm{f}}\right)$}

4.4 The effects of coping costs on the evolutionary strategy of stakeholders are investigated by changing $C_{f}$ while fixing other parameters. Simulation results in Figure 8 reveals that the time for farmers to choose cooperative strategies is shortened when coping costs increase from 1 to 7 . In other words, in the same time, farmers are more likely to choose cooperative strategy when coping costs are greater. Findings indicate that stakeholders will adopt cooperative strategies when costs are too high for them to protect their rights, and the probability of triggering conflicts is lower under this circumstance. This outcome is echoed by the practice wherein farmers unify as one group to seek more benefits if the individuals find difficulty in bargaining with the local government or its agents.

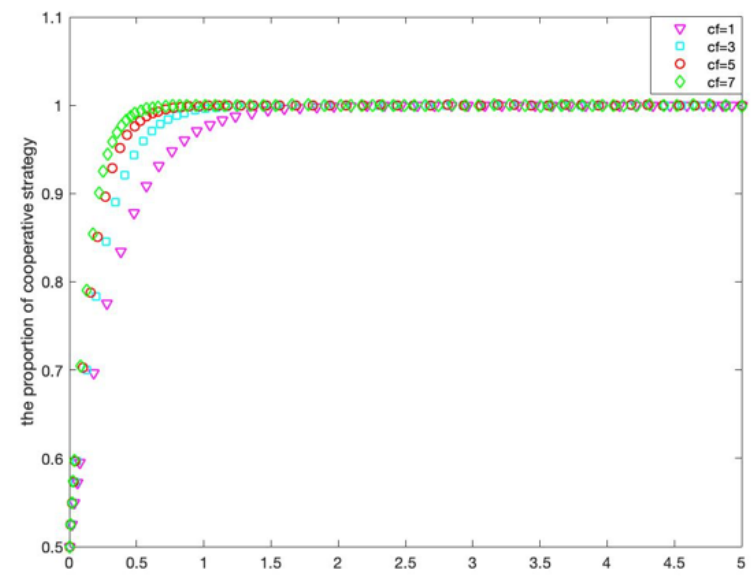

Figure 8: The effects of the coping cost on the evolutionary strategy of farmers.

\section{Discussion on the Simulation Results}

\section{Implications of simulation results}

5.1 From the above simulation results, we conclude that farmers involved in land expropriation will adopt different responses to the conflict of interests. 
5.2 When the level of land expropriation compensation for all farmers is extremely high and cooperative costs are low, boycott costs are high, namely, $R_{0}>2\left(C_{0}-C_{f}\right)$. Simultaneously, the payment of farmers who chose the cooperative strategy is higher than that under non-cooperative strategy. the final evolutionary result must be an increased number of farmers who select the cooperative strategy.

5.3 When the land expropriation compensation provided by the local governments is lower or the cooperative costs of farmers involved in land expropriation are much higher than that incurred in the non-cooperative strategy, then, $R_{0}<C_{0}-C_{f}$. In this case, the payment of the farmers who selected the cooperative strategy will be less than that of the non-cooperative strategy. Furthermore, the final evolutionary result must be an increased number of farmers who select the non-cooperative strategy.

5.4 In reality, local governments are under a certain cost, and the benefits obtained by farmers occur in a varying range of cooperative costs, namely, $C_{0}-C_{f}<R_{0}<2\left(C_{0}-C_{f}\right)$. The number of farmers who chose cooperative and non-cooperative strategies is close to a stable equilibrium level after several generations of the evolutionary game, which confirms the condition $x_{3}^{*}=\frac{2\left(R_{0}-C_{0}+C_{f}\right)}{R_{0}}$. In this case, three possibilities may occur: (1) When the proportion of farmers who choose the non-cooperative strategy in this equilibrium level is large, resistance among villagers will occur. (2) When the proportion of farmers who choose the cooperative and non-cooperative strategies is approximately the same, conflict with the villagers will also occur. (3) When the proportion of farmers who select the non-cooperative strategy in this equilibrium level is small, "nail households" will occur.

\section{Means to promote cooperation of farmers involved in land expropriation}

5.5 In this section, we propose two ways of promoting the cooperation of farmers involved in land expropriation by means of the simulation results above: reducing the variation of cooperative costs and increasing the total amount of income obtained from land expropriation.

5.6 Two methods can be selected to reduce the variation of cooperative costs, $\left(C_{0}-C_{f}\right)$. On the one hand, the government can take some measures to increase the cost of resistance $\left(C_{f}\right)$, including punishing farmers who provoke resistance to land expropriation, and reducing cooperative awards. On the other hand, the government can reduce cooperative costs $\left(C_{0}\right)$, such as by establishing land expropriation of the green channel to simplify procedures and processes to improve the efficiency of dispute handling and increasing the resettlement compensation to reduce the executory costs of the farmers.

5.7 The government can also increase the total amount of income $\left(R_{0}\right)$. Local governments can encourage noncooperative farmers by offering them appropriate policy concessions or other rights that do not exceed the reasonable range of game conditions in this study to ensure that the payment of farmers adopting the cooperative strategy is higher than those who adopt the non-cooperative strategy.

\section{Conclusion}

6.1 Existing studies on land expropriation conflicts are based mainly on structuralism and focus on static normative research, case analysis, and subjective experience summary. However, these studies lacked a bottom-up modeling of the evolution of expropriation and demolition conflict, as well as quantitative systematic study. On the basis of the existing studies, the current study constructs an evolutionary game model and carries out a simulation experiment to analyze the different responses to the conflict of interests in land expropriation. From the experiment, farmers will adopt different strategies based on the variation of $R_{0}, C_{0}$ and $C_{f}$ to cope with potential conflicts of interests. Under different conditions, the evolutionary trend of farmers' strategies will tend to be stable. Therefore, local governments can effectively promote cooperation of farmers in accordance with the most reasonable cost range based on different evolutionary outcomes of simulation, including reducing the variation of cooperative costs and increasing the total amount of income obtained from land expropriation.

6.2 However, a series of problems are encountered during the research. First, the strategy and condition of the conflict of collectively owned land expropriation game are defined and remained partial and idealized in the evolutionary game model constructed by this study. For example, the efficiency of information transmission and endowment effect among game agents should be considered in reality. Second, this study applies the simulation modeling method into land expropriation conflicts among farmers, which remains in the primary stage of exploration. The population density on the effect of land expropriation and other aspects in the simulation platform can still go further. Therefore, future studies should also consider the points presented above. 


\section{Disclosure statement}

The authors declare they have no conflict of interest in this work.

\section{Acknowledgements}

This work was supported by National Natural Science Foundation of China (41371187; 71503228), Natural Science Foundation of Zhejiang Province of China (LQ16G030006), Qianjiang Talents Program of Zhejiang Province (QJC1602006), and Philosophy and Social Sciences Planning Project of Hangzhou (M17JC032).

\section{References}

Alston, L. J., Libecap, G. D. \& Mueller, B. (2000). Land reform policies, the sources of violent conflict, and implications for deforestation in the Brazilian Amazon. Journal of Environmental Economics and Management, 39(2), 162-188

Amman, H. M. \& Duraiappah, A. K. (2004). Land tenure and conflict resolution: A game theoretic approach in the Narok district in Kenya. Environment and Development Economics, 9(3), 383-407

Bao, H. J., Deng, S., Xu, S. \& Peng, Y. (2017). Conspicuous consumption behavior of land-lost farmers: A perspective of social identity. Cities, 66, 81-90

Bao, H. J. \& Peng, Y. (2016). Effect of land expropriation on land-lost farmers' entrepreneurial action: A case study of Zhejiang Province. Habitat International, 53, 342-349

Bao, H. J., Peng, Y., Ablanedo-Rosas, J. H. \& Gao, H. (2015). An alternative incomplete information bargaining model for identifying the reasonable concession period of a BOT project. International Journal of Project Management, 33(5), 1151-1159

Bao, H. J., Ye, Q.-y. \& Xu, S.-M. (2014). Conflict and governance of rural collective-owned land expropriation: An interdisciplinary literature comment. China Land, 28(9), 82-88

Bao, H. J., Zhu, X., Cen, Y., Peng, Y. \& Xue, J. (2018). Effects of social network on human capital of land-lost farmers: A study in Zhejiang Province. Social Indicators Research, 137(1), 167-187

Baranyi, S. \& Weitzner, V. (2006). Transforming land-related conflict: Policy practice and possibilities. Working Paper for the North-South Institute

Barreteau, O., Bousquet, F. \& Attonaty, J.-M. (2001). Role-playing games for opening the black box of multi-agent systems: Method and lessons of its application to Senegal River Valley irrigated systems. Journal of Artificial Societies and Social Simulation, 4(2), 5

Boydell, S. (2001). Land tenure and land conflict in the South Pacific. Land Reform, Land Settlement and Cooperatives

Boydell, S. (2003). Land and volence in post-conflict situations. Report prepared for The North-South Institute and The World Bank (5)

Chen, Y., Tan, S. K. \& Zhang, A. L. (2009). A study on the difference between the compensation for the public land-requisition and that for the private land-requisition. Management World, 10(1), 72-79

Cheng, J. (2006). The injustice and reconstruction of procedures in eminent domain and land acquisition. Chinese Journal of Law, 1, 62-78

De Wit, P. V. D. (2002). Land conflict management in Mozambique: A case study of Zambezia Province. Land Reform, 2, 19-34

Ding, C. \& Lichtenberg, E. (2011). Land and urban economic growth in China. Journal of Regional Science, 51(2), 299-317 
Ding, W. (2007). Analysis on causes of tort in land expropriation and countermeasures. China Land Science, 21(4), 54-59

Douma, A. M., van Hillegersberg, J. \& Schuur, P. C. (2012). Design and evaluation of a simulation game to introduce a multi-agent system for barge handling in a seaport. Decision Support Systems, 53(3), 465-472

Fang, Y. M. \& Chen, Y. (2007). Reflections on optimized allocation of resources in urban demolishing and removal. Journal of Fujian Provincial Committee Party School of CPC, 6, 26-29

Filatova, T., Parker, D. \& Van der Veen, A. (2009). Agent-based urban land markets: Agent's pricing behavior, land prices and urban land use change. Journal of Artificial Societies and Social Simulation, 12(1), 3

Fischel, W. A. \& Shapiro, P. (1988). Takings, insurance, and Michelman: Comments on economic interpretations of "Just Compensation" Law. The Journal of Legal Studies, 17(2), 269-293

Friedman, D. (1998). On economic applications of evolutionary game theory. Journal of Evolutionary Economics, $8(1), 15-43$

He, S. X. (2013). Land security and farmers' social security: Conflict and coordination. Academic Journal of Zhongzhou, 2, 31-35

Hotte, L. (2001). Conflicts over property rights and natural-resource exploitation at the frontier. Journal of Development Economics, 66(1), 1-21

Huang, Z. \& Wang, H. (2002). Land expropriation for a non-public purpose and compensation for its development right. Economic Research Journal, 5, 66-71

Jin, X. M. \& Chen, X. (2017). The holdout problem in the process of land assembly in America and its implications. Journal of Zhejiang University (Humanities and Social Sciences), 47(3), 183-193

Ke, X. B. \& He, G. C. (2006). Study on the reform of land expropriation system within 3-level game relationships - Based on analysis of land expropriation procedure of one university town. China Land Sciences, 20(3), 4-8

Le Bars, M. \& Le Grusse, P. L. (2008). Use of a decision support system and a simulation game to help collective decision-making in water management. Computers and Electronics in Agriculture, 62(2), 182-189

Lee, C.-Y. (2018). Mixed-strategy Nash equilibrium in data envelopment analysis. European Journal of Operational Research, 266(3), 1013-1024

Li, H. B. (2007). Study on land conflict in the process of expropriation. Ph.D. thesis, Huazhong University of Science and Technology

Li, H. B., Tan, S. K. \& You, H. Y. (2006). The problem of land conflict in contemporary China and the search for its source. Tian Fu New Idea (Bimonthly), 6, 60-63

Li, Q., Bao, H. J., Peng, Y., Wang, H. \& Zhang, X. (2017). The collective strategies of major stakeholders in land expropriation: A tripartite game analysis of central government, local governments, and land-lost farmers. Sustainability, 9(4), 648

Liang, X., Peng, Y. \& Shen, G. Q. (2016). A game theory based analysis of decision making for green retrofit under different occupancy types. Journal of Cleaner Production, 137, 1300-1312

Liu, X., Chen, Z. \& Zhao, Y. (2012a). The procedural fairness prior to the monetary compensation: The determinants of the degree of farmers' satisfaction at levying their land. Management World, 2, 44-51

Liu, X. Q., Chen, Z., Tian, X. J. \& Li, G. (2012b). Monetary compensation for land expropriation and its influencing factors: A survey of land rights and interests in 17 provinces. Chinese Rural Economy, 12, 32-40

Liu, Z. Y. \& Chen, M. (2012). From "land conflict" to "land risks": Theoretical prospect on land issues in rural China. China Land Sciences, 26(8), 23-28

Luo, X. (2009). Game theory analysis of land conflicts in the procedure of urbanization in Jiangxi. Science Mosaic, $12,84-87$

Meng, H. B. (2010). Social construction of problems under resource mobilization: The formation mechanism of rural land expropriation conflicts. Modern Economic Science, 32(5), 119-123 
Nishino, N., Okazaki, M. \& Akai, K. (2017). Effects of ability difference and strategy imitation on cooperation network formation: A study with game theoretic modeling and multi-agent simulation. Technological Forecasting and Social Change, 136, 145-156

Peng, Y. (2015). A comparison of two approaches to develop concentrated rural settlements after the 5.12 Sichuan earthquake in China. Habitat International, 49, 230-242

Peng, Y., Shen, L., Zhang, X. \& Ochoa, J. J. (2014). The feasibility of concentrated rural settlement in a context of post-disaster reconstruction: A study of China. Disasters, 38(1), 108-124

Peng, Y., Zhang, F. Y., Jiang, S. L., Huang, L., Wang, Z. M. \& Xu, Y. L. (2018a). Analysis of farmers' satisfaction towards concentrated rural settlement development after the Wenchuan earthquake. International Journal of Disaster Risk Reduction, 31, 160-169

Peng, Y., Zhu, X., Zhang, F., Huang, L., Xue, J. \& Xu, Y. (2018b). Farmers' risk perception of concentrated rural settlement development after the 5.12 Sichuan earthquake. Habitat International, 71, 169-176

Perry, E. J. \& Wong, C. (1985). The Political Economy of Reform in Post-Mao China. Cambridge, MA: Harvard University Press

Phillips-Alonge, O. K. (2018). The influence of partnering on the occurrence of construction requirement conflicts and disputes. International Journal of Construction Management, (pp. 1-16)

Polhill, J. G., Sutherland, L.-A. \& Gotts, N. M. (2010). Using qualitative evidence to enhance an agent-based modelling system for studying land use change. Journal of Artificial Societies and Social Simulation, $13(2), 10$

Ramirez, R. (2002). A conceptual map of land conflict management: Organizing the parts of two puzzles. Paper Produced for FAO

Schwarz, N., Kahlenberg, D., Haase, D. \& Seppelt, R. (2012). ABMland - A tool for agent-based model development on urban land use change. Journal of Artificial Societies and Social Simulation, 15(2), 8

Shen, K. J. (2006). Expropriation, Requisition and Compensation. Beijing: Law Press

Tan, S. K. (2006). Analyses on land expropriation and the loss of rights attached to the land. Finance \& Economics, $1,88-92$

Tan, S. K. \& Qi, R. (2010). Analyzing land expropriation conflicts in China based on a newly-built game model. China Land Sciences, 24(3), 25-29

Tan, S. K. \& Tu, T. (2009). The game theory analysis on the stakeholders involved in farmland-acquisition conflicts: Taking the local government and land-lost peasants as an example. China Land Sciences, 23(11), 27-31

Tang, L. M. (2009). A study on the contradictions of land expropriation and housing demolition in the current process of urbanization in china - based on the visual threshold of policy networks. Ph.D. thesis, Jilin University

Tu, S. (2009). Study on rural land conflicts in the transitional period. Ph.D. thesis, Huazhong University of Science and Technology

Wang, P. (2007). Analysis on the game path of main interest body in current agricultural land requisition. Issues in Agricultural Economy, 10, 34-40

Wehrmann, B. (2008). Land conflicts: A practical guide to dealing with land disputes. Deutsche Gesellschaft für Internationale Zusammenarbeit Gmbh

Weibull, J. W. (1996). Evolutionary Game Theory. Cambridge, MA: MIT Press

Windrum, P., Fagiolo, G. \& Moneta, A. (2007). Empirical validation of agent-based models: Alternatives and prospects. Journal of Artificial Societies and Social Simulation, 10(2), 8

Wu, Y., Mo, Z. \& Peng, Y. (2017). Renewal of land-use term for urbanization in China: Sword of Damocles or Noah's ark? Land Use Policy, 65, 238-248

Wu, Y., Mo, Z., Peng, Y. \& Skitmore, M. (2018). Market-driven land nationalization in China: A new system for the capitalization of rural homesteads. Land Use Policy, 70, 559-569 
Xie, S. (2010). Economic Game Theory. Shanghai: Fudan University Press

Yang, H. (2013). Class conflicts in rural land requisition and demolition - A case study of rural land disputes in suburbs of Jingmen City. Academic Journal of Zhongzhou, 2, 70-76

Yang, X., Hao, X. Y., Wang, C. M. \& Sun, B. F. (2008). Study of fair plans for land expropriation and compensation. China Land Sciences, 22(3), 4-10

Ye, J. P., Ma, C. F. \& Zhang, Q. H. (2011). Contribution of land to the economic growth of China: Based on spatial panel data model. Finance \& Trade Economics, 4, 111-116

Yuan, K. (2015). The "One Body and Two Aspects" of negotiation: A comparative perspective based on "NIMBY conflict" and land expropriation and demolition conflicts. Tribune of Study, 31(10), 51-55

Zhang, C. H., Deng, L., Qiu, D. C., Yang, H. M. \& Li, B. H. (2005). An analysis of the psychological characteristics of landless peasants in land expropriation. Rural Economy, 9, 116-118

Zhang, G. X. (1990). Research and application of risky conflict analysis model. Master thesis, Tianjin University

Zhang, Z. L. (2009). Interest conflicts, compensation system and policy adjustment of land expropriation in the rural area. Qilu Journal, 3, 84-89

Zhong, K. B. (2009). Review and prospect: the construction of China's emergency management system. CASS Journal of Political Science, 1, 78-88

Zhong, W. (2013). Conflicts behavior analysis and public governance ideals of land expropriation interest game in urbanization process. Modern Economic Research, 4, 28-31

Zhou, Q. R. (2004). Farmland property right and land expropriation system - A major choice for China's urbanization. China Economic Quarterly, 4, 197-214

Zhu, T. Z. (2013). The rural land expropriation conflict and governance from the perspective of national and social relationship. The Journal of Shanghai Administration Institute, 3, 96-103

Zou, X. Q. \& Oskam, A. J. (2007). New compensation standard for land expropriation in China. China \& World Economy, 15(5), 107-120

Zou, X. Q., Zhong, X. Y., Xiao, Z. G. \& Song, X. (2012). Dynamic game analysis among local government, central government, and peasants in the conflicts of farmland acquisition. China Land Sciences, 26(10), 54-60 